\title{
Detection of patterns and trends in patient behavior while using electronic applications and Internet resources for self-diagnosis
}

\author{
Galina A. Polynskaya \\ Associate Professor, Department of Marketing \\ Lomonosov Moscow State University \\ Address: 1, Leninskie Gory, Moscow, 119991, Russian Federation \\ E-mail: g.polinskaya@outlook.com
}

\section{Margarita G. Mesropyan}

Doctoral Student, Economic Sociology and Demography Specialty Financial University under the Government of the Russian Federation Address: 49, Leningradsky Prospekt, Moscow, 125993, Russian Federation

E-mail:m.mesropyan.93@gmail.com

\begin{abstract}
Information and communication technologies have changed the world, affecting all sectors of the national economy including the medical industry. There is rapid growth in the dependence of the quality of medical services on the use of information systems. Gradually, information systems are beginning to take over part of doctors' work. Digitalization also has affected ordinary citizens. There is a growing popularity of electronic applications and Internet resources in the health care industry among users of the network. As a result, self-diagnosis and self-treatment are improving with their use. Therefore, it is important to assess the possibilities for the coexistence of traditional medicine with modern digital technology opportunities that the citizens are facing these days.

The authors of this research have carried out a series of studies to identify the patterns of patient behavior using electronic applications and Internet resources for self-diagnosis, as well as factors that contribute to or impede the development of such use. The following actions were performed: high-quality content analysis of medical web applications, 40 in-depth interviews with doctors and pharmacists, a mini focus group with representatives of the health service, as well as an online survey of two hundred respondents in the social network Facebook.

As a result of the study, patients were segmented according to typical behavioral patterns with regard to the use of electronic applications and Internet resources in the field of medicine. We identified the attitude towards Internet self-diagnosis of doctors and pharmacists on the one hand and patients, on the other, as well as factors contributing to or impeding the growth of Internet diagnostics.
\end{abstract}

Key words: digitization of health care, electronic technologies, Internet applications, clinical diagnostics, mobile software, digital medicine.

Citation: Polynskaya G.A., Mesropyan M.G. (2018) Detection of patterns and trends in patient behavior while using electronic applications and Internet resources for self-diagnosis. Business Informatics, no. 1 (43), pp. 28-38. DOI: 10.17323/1998-0663.2018.1.28.38. 


\section{Introduction}

I nformation and communication technologies have changed the world, affecting all sectors of the economy. The economy has become directly dependent on software, computer and network equipment, as well as systems for obtaining, analyzing, storing and distributing information, largely built on network technologies. These changes among other things affected the health care sphere radically.

While working with information in medical practice, paper (solid) carriers are still largely used, but information technology is rapidly supplanting this approach. The time is approaching when all medical information will be transformed into digital. Likewise, the approach of decision making in diagnosis and treatment is changing. Whereas previously, besides instrumental research and analysis, the knowledge and experience of the doctor were determinants, now, for instance, digital information systems with elements of decision support are of great importance for qualitative diagnostics and solving problems of patients. These changes have also been used by pharmaceutical companies, which brought a large number of medical applications into "virtual space." As a result, not only doctors, but also patients were able to participate in the diagnosis of their own diseases. This confirms the relevance of the study, namely:

$\downarrow$ the gradual digitalization and distribution of information systems in health care, and the growing dependence of the quality of medical services on digital technologies;

- the growing popularity among users of electronic applications and Internet resources in the field of medicine, and as a consequence the growth of self-diagnosis and self-treatment. Back in 2012, Deloitte looked into the online segment of consumers in health care, estimating it to be $17 \%$ [1]. These are active users of electronic applications and Internet resources in the field of medicine; $\downarrow$ consequently, there is a need to assess the possibilities for the coexistence of traditional medicine and the new opportunities that citizens face with modern digital technologies.

As the purpose of our study, we focused on identifying the patterns of patient behavior using electronic applications and Internet resources for self-diagnosis, as well as factors contributing to or impeding the development of such use.

To achieve this goal, the following tasks were accomplished:

$\diamond$ study of the existing models of citizens' behavior in case of medical problems in conditions of medical information digitalization;

clarification of the views of these models among doctors, pharmacists and consumers of medical services (patients).

The research methodology consisted of several stages:

1. Conducting high-quality content analysis of medical web applications through the Yandex search system.

2. Interviewing doctors and pharmacists. The study was conducted from 22.10.2016 to 10.11.2016 in a city with a population of more than one million people, and consisted of interviews with:

- twenty general practitioners working in 18 polyclinics, both private and public. All respondents were women between the ages of 35 and 60 ;

- twenty pharmacists working in pharmacies of the city, of which $95 \%$ were women and $5 \%$ were men, aged 25 to 40 years;

- one mini focus group consisting of three doctors and one pharmacist working in the health services control department.

3. An online survey of users in the social network Facebook. The study was conducted during the period from 28.01.2017 to 20.02.2017. As a result, 200 respondents were interviewed. Distribution by gender was uneven: the female audience is $63 \%$ of the respondents. It was taken into account that the female population is more 
concerned with their health and makes up the majority of the population (according to FSSS data, about $54 \%$ of the total population of the Russian Federation in 2017). The distribution of respondents by age groups is also uneven: $59 \%$ of respondents fall in the range of 18 to 24 years old, $29 \%$ of respondents are from 25 to $35,6 \%$ are from 36 to $45,4 \%$ are from 46 to $55,2 \%$ - over 55 years old. The sample was voluntary, so the age distribution of respondents does not correspond to the general population, but is similar to the distribution of active users of the network.

The research is exploratory; the researchers did not set a task of identifying exact data, but only of identifying existing problems and trends.

\section{Factors affecting the market development for electronic and Internet applications in the medical field}

The main factors affecting the development of electronic applications and Internet resources market in the medical field are:

$\downarrow$ the wide penetration of the Internet in Russia, comparable with developed countries; a significant increase in the use of the Internet on mobile devices;

$\checkmark$ gradual smoothing of age and geographical differentiation of Internet users in Russia;

$\checkmark$ rapid growth of "digital" health care.

According to a study conducted by consulting company Arthur D. Little [2], the world market of "digital" health care will grow by more than three times by 2020 and reach $\$ 233.3$ billion [2]. In this case, according to company analysts, mobile solutions will be successful in the near future. Thus, the growth of mobile health in the period from 2017 to 2020 will be more than $130 \%$. The main advantages of mobile health care are ubiquitous access to health services and individual health solutions [3], which facilitates faster delivery of medical services, provides lower costs and provides wider access to health services of higher quality. Therefore, it is expected that mobile health care will improve the quality of medical services for consumers [4].

\subsection{Growth of electronic and Internet applications in the field of medicine announced and distributed by pharmaceutical companies}

Many leading pharmaceutical companies have managed to develop and test electronic and Internet applications for the diagnosis and prevention of diseases. Currently, there are more than 20,000 medical applications available only in the App Store. Applications in the "mobile health care" category are the third fastest growing category of applications both for iOS and Android. It is expected that by 2018, more than $50 \%$ of 3.4 billion users of smartphones and tablets will download mobile applications from the health care field [5].

\subsection{Free access to professional electronic and Internet applications for diagnosis of diseases}

A. Yutel (Victoria University) and D. Lupton (University of Canberra) in 2013 conducted a content analysis of medical applications available in the Google Play Store and the App Store. The task was to determine which applications for medical diagnostics are offered in the net. The search for applications was carried out by the key phrase - "medical diagnosis," and the result produced 176 applications. In the aftermath, only applications in English focusing on traditional methods of treatment were chosen. As a result, 131 applications remained, 57 of which belonged to the clinical diagnosis type [6]. Runet offers no fewer applications in the field of medicine, while the range of tasks they solve is growing every day. The most typical applications are shown in Table 1 (author's scheme, compiled based on the results of content analysis).

\subsection{Increased involvement of patients in the health sector}

The concept of empowerment of patients is spreading everywhere (Figure 1). The focus is on encouraging patient's individual selection 


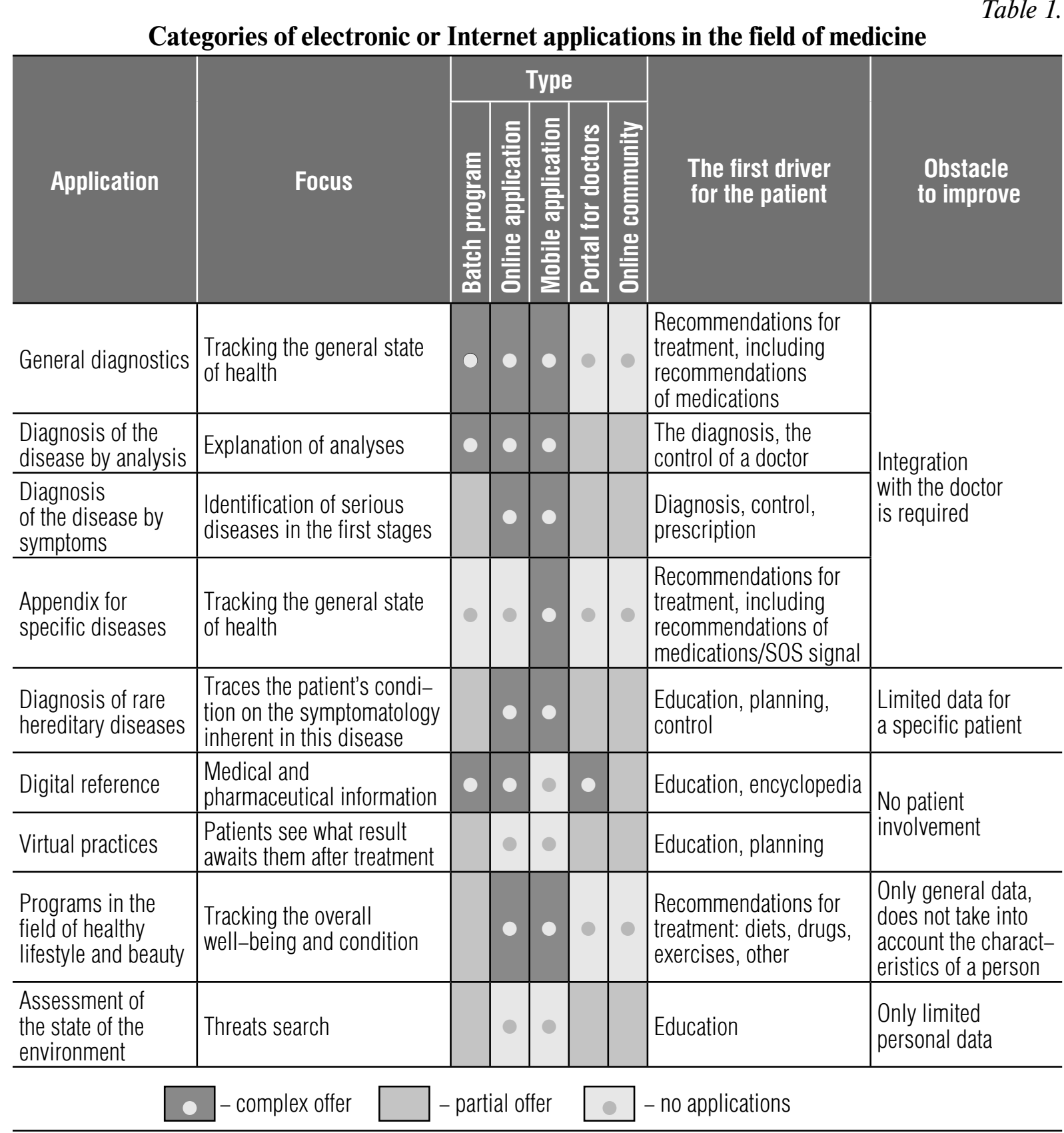

in the field of treatment [7] and involving public organizations to develop mechanisms for providing quality medical care [8].

\section{Consumer behavior perception analysis in the opinion of doctors and pharmacists}

Based on the analysis of in-depth interviews with doctors and pharmacists, several schemes of consumer behavior were drawn up. The estimates presented in the schemes were accomplished by the Delphi method. The con-sumers (patients) were classified into three groups: "traditionalists" (with "doubters" sub-group), "searchers," and "generation Y."

Many consumers buy medications from the nearest pharmacies without first visiting a doctor, based on previous experience, or on the 


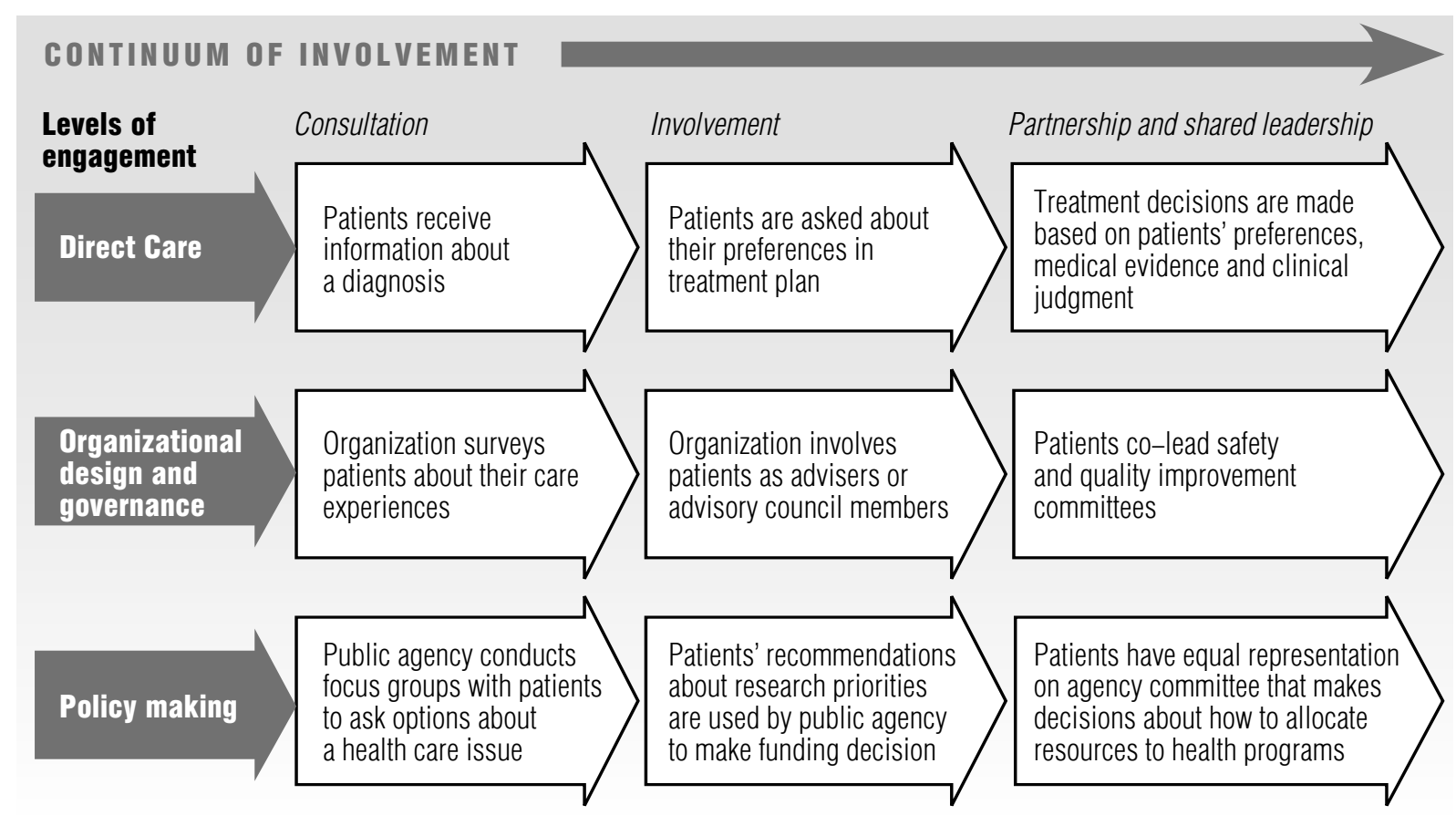

Fig. 1. Possible participation of patients in health care

recommendations of the nearest environment, or after consulting a pharmacist. If the use of medications does not have a positive effect, then the behavior of consumers may be different:

"Traditionalists" (Figure 2) trust traditional methods of treatment; they will turn to the doctor.

After the diagnosis is established, the majority of patients will start the course of treatment without questioning the authority of the attending physician, and fulfilling most of the prescriptions, including the intake of medications. However, some patients "doubters" - after going to the doctor will necessarily visit virtual space in order to learn more about the diagnosis and read reviews about the drugs. According to respondents, over time the share of "doubters" among "traditionalists" will only increase. If the information obtained from the Internet meets the recommendations of doctors, the patient proceeds to the course of treatment. Otherwise, the patient may question the diagnosis or a treatment that may lead to an unpredictable reaction. For example, he or she will still break into the course of treatment, or replace some of the drugs with others, using recommendations received on the Internet, or consult with pharmacists (pharmacy workers very often change the drugs).

"Searchers" (Figure 3) is a subgroup of people who are trying to find out independently about problems, including medical problems.

After an unsuccessful attempt at self-treatment, representatives of this group seek advice in the Internet, trying to solve the problem on their own. If, in their opinion, the answer is found, they bravely buy or order the recommended medications. Only if the use of medicines does not have a positive effect do they turn to the doctor. At the same time, they are sure to search the Internet for information about the diagnosis and prescribed medications. Only if the information received on the Internet meets the recommendations of doctors, the patient proceeds to the course of treatment, fulfilling most of the prescriptions, including the intake of medications.

"Generation Y" (Figure 4) - patients of the "new rhythm of life" who value their time and freely own modern gadgets, "living in the web." Over time, according to respondents, this group of patients will only increase. 


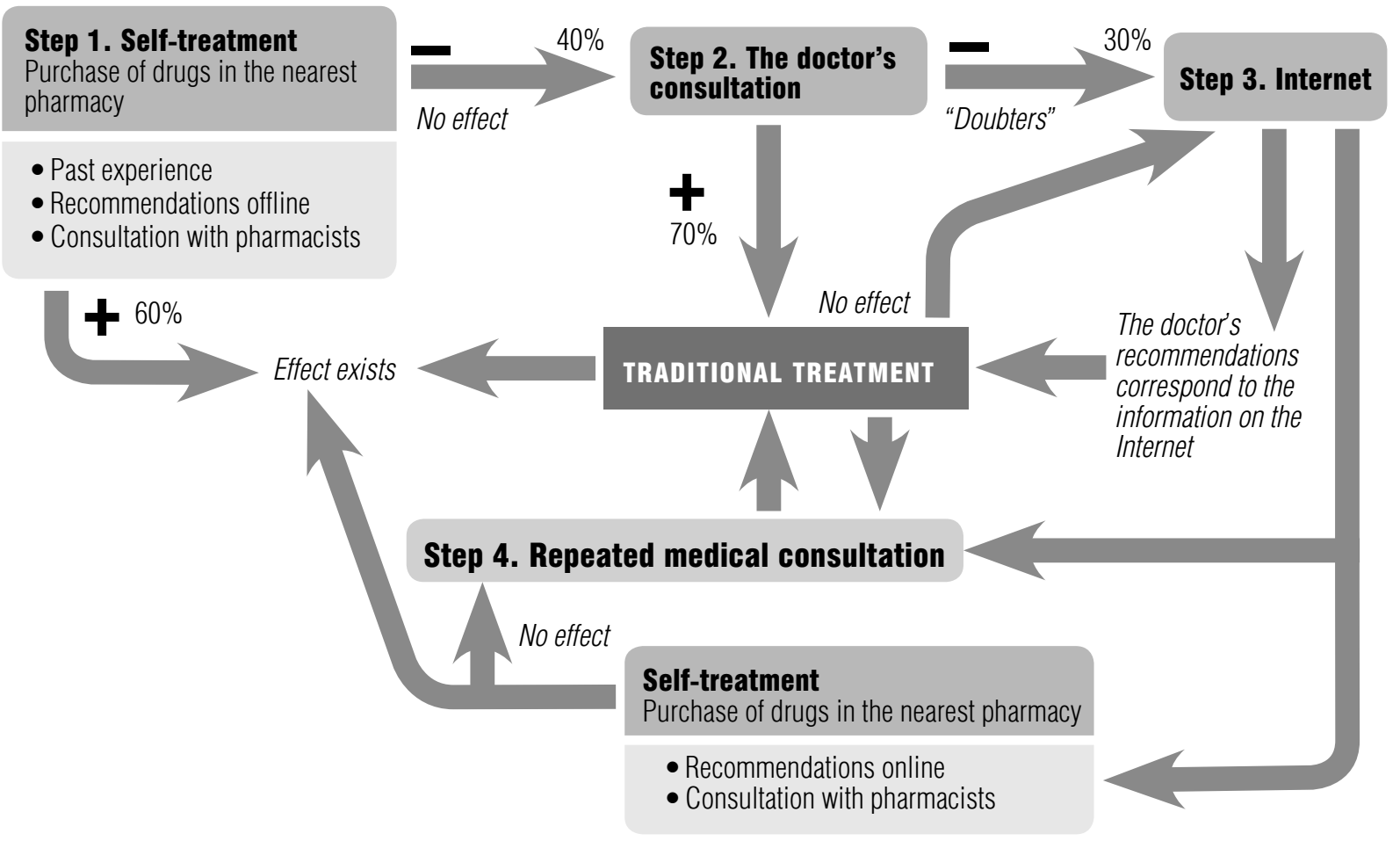

Fig. 2. The scheme of consumer behavior with a short-term implicit manifestation of the disease, "traditionalists"

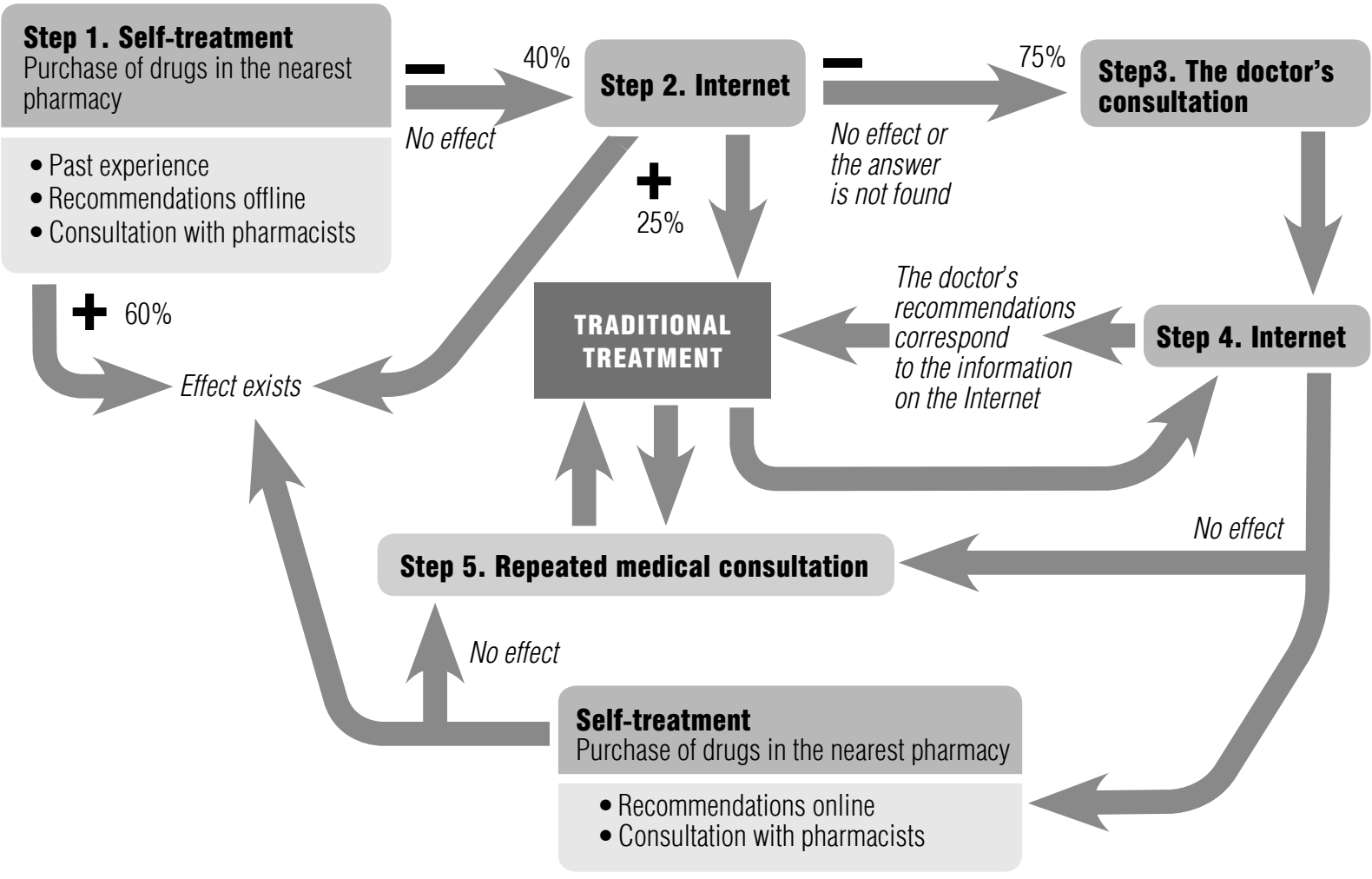

Fig. 3. Scheme of consumer behavior with a short-term implicit manifestation of the disease, "searchers" 


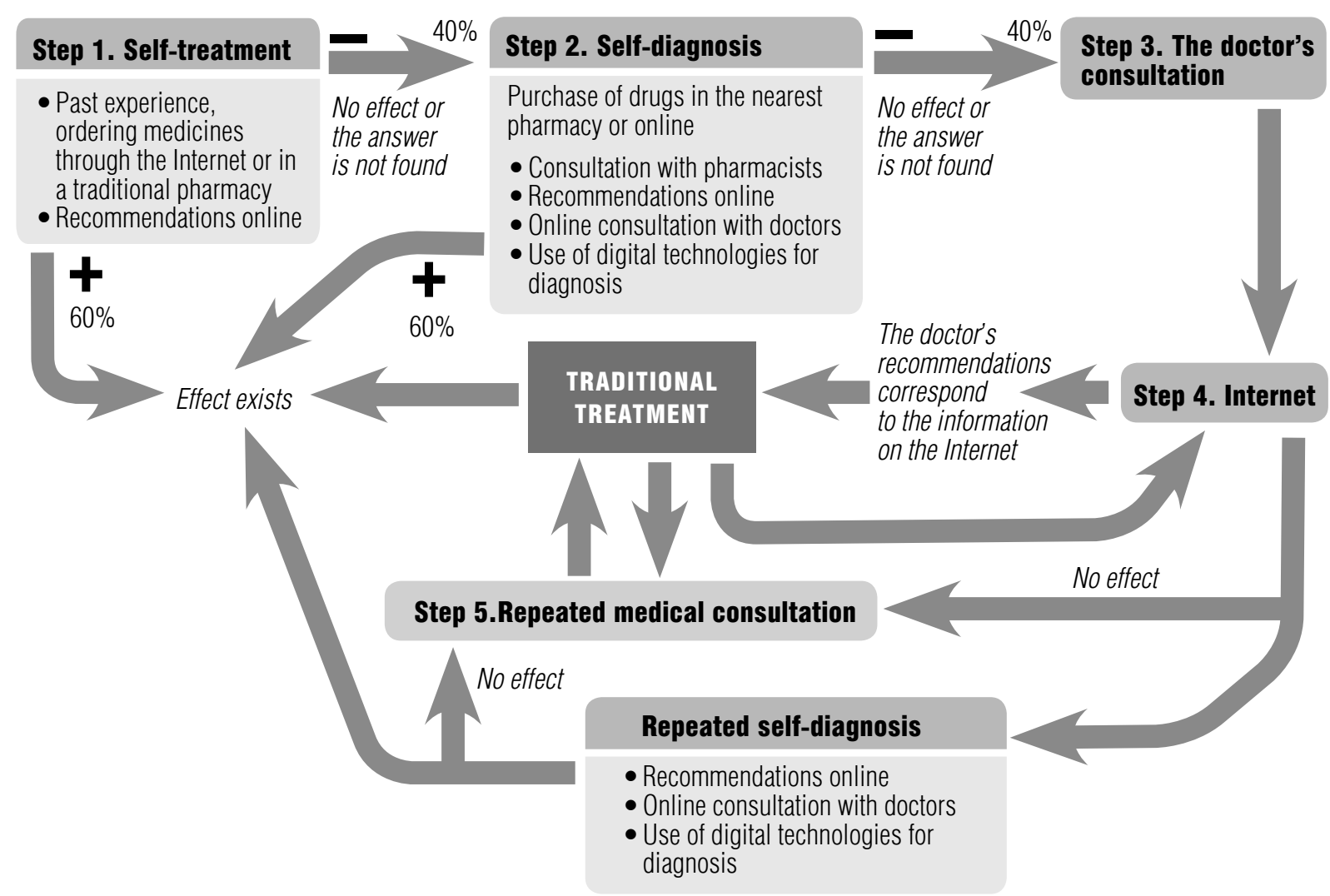

Fig. 4. Scheme of consumer behavior with a short-term implicit manifestation of the disease, "generation Y"

If there is experience in the treatment of these diseases, representatives of this group buy medication often in online stores. In the case of unusual symptoms, the first thing they do is go to the Internet to search for information: they conduct self-diagnostics through Internet services, read instructions and reviews on recommended medications. Often, after an unsuccessful attempt at self-treatment, they continue their independent diagnosis, while they can go to the pharmacy for clarifying advice. Only if there is no positive effect, will they go to the doctor, while often questioning the diagnosis.

The behavior of patients varies greatly if syndromes are pronounced. In this case, patients refuse to self-cure and immediately call the doctor at home, regardless of their opinion. This does not exclude the possibility of consulting with pharmacists and searching the net for information about the disease.
Strong differences in the analysis of in-depth interviews with doctors and pharmacists are not observed. In general, doctors are supportive of Internet diagnostics of patients, believing that this trend is the future. At the same time the following are considered to be the main factors when choosing a method of treatment and diagnosis (Table 2).

Table 2.

\section{Factors affecting the pattern of patient behavior in the search for treatment}

\begin{tabular}{|c|c|c|}
\hline $\begin{array}{l}\text { Consultation with } \\
\text { doctors }\end{array}$ & $\begin{array}{c}\text { Consultation } \\
\text { with } \\
\text { pharmacists }\end{array}$ & $\begin{array}{l}\text { Information } \\
\text { searchthrough } \\
\text { the Internet }\end{array}$ \\
\hline $\begin{array}{l}\text { - fear of complications; } \\
\text { - moral support; } \\
\text { - belief in professiona- } \\
\text { lism and competence. }\end{array}$ & $\begin{array}{l}\text { - fast receipt } \\
\text { of advice; } \\
\text { - availability; } \\
\text { - trust. }\end{array}$ & $\begin{array}{l}\text { - informative; } \\
\text { - fast information } \\
\text { retrieval; } \\
\text { - availability. }\end{array}$ \\
\hline
\end{tabular}




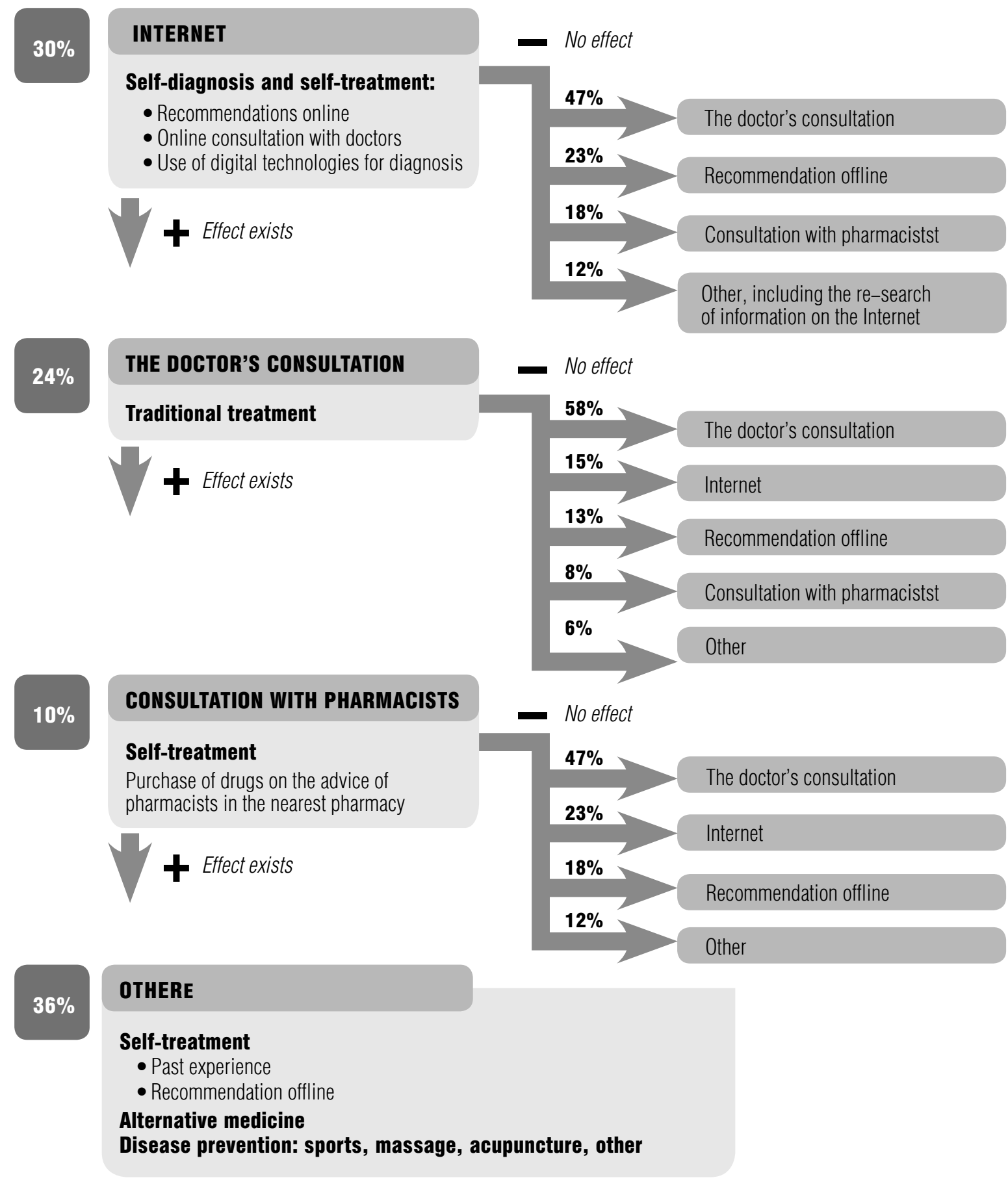

Fig. 5. The scheme of consumer behavior

Factors that prevent the development of selfdiagnosis using electronic applications and Internet resources are a high risk of misdiagnosis, which can be the result of (1) incorrect assessment of one's own condition, (2) incomplete collection of anamnesis, (3) incom- plete or incorrect semiotics (not all or excessive signs of the disease have been introduced), (4) application failures. The consequence may be the incorrect diagnosis or misapplication of drugs with the help of the program (allergy, excessive use, the use of incompatible drugs). 
That is why the main opponents of Internet diagnostics are government officials. The focus group members noted, “... that this practice is very dangerous for use, as it is directly related to the health of citizens and can cause great harm." In addition, the authorities remind us that it is illegal to buy certain medications without a doctor's prescription.

\section{Patients' consumer behavior analysis based on consumer survey results}

For the primary segmentation of respondents by behavior, the following question was used: "If you have any painful symptom or other manifestation of a disease, what will you do?" The respondent had to choose one answer. The results were distributed as follows: "I will read information on the Internet" (30\% of respondents), "I'll go straight to the doctor" (24\%), "I'll consult with friends or acquaintances" (15\%), "I'll take a pain reliever that I consider appropriate for the situation" (12\%), "I'll go to the pharmacy" (10\%), "Difficult to answer"(9\%).

On the basis of primary segmentation, a scheme of consumer behavior was drawn up (Figure 5). It does not take into account extremely heavy or light conditions, since we assume that self-treatment with an implicit pain syndrome is applied more often, i.e. in the case of a mild headache, the majority of respondents (98\% of respondents) will simply take an analgesic pill. With a strong pain syndrome or in case of fear for one's health, all respondents will immediately turn to a doctor.

The compiled scheme confirms the results obtained by analyzing in-depth interviews with physicians and pharmacists detailing them. In other words, we can assume that "traditionalists" make up only $24 \%$ of respondents, while $65 \%$ of this group can be classified as "doubters." To the question about their readiness after the doctor's diagnosis to visit virtual space to learn more about the diagnosis and read the reviews about the drugs, only $30 \%$ of the respondents answered negatively, and $15 \%$ expressed absolute readiness for this solution. At the same time, $24 \%$ of respondents are likely to look for information on the network, and $26 \%$ will probably look for information.

The share of "generation Y" is $30 \%$. As anticipated by doctors and pharmacists, this group is likely to grow soon, since the following question "Do you think it's right to read information on the Internet about the illness or carry out an Internet diagnosis of the disease before visiting a doctor?", $50 \%$ of the respondents answered that they consider this to be correct behavior.

An interesting fact is that $28 \%$ of respondents already use Internet applications for diagnosis of diseases based on symptoms.

The remaining $46 \%$ of respondents, unfortunately, cannot be accurately divided into segments, but form the following mixing groups:

४ "searchers";

४ "healthy lifestyle" - respondents who lead a healthy lifestyle and as a result prefer not to take any medications without strong need, often turning to alternative medicine, main-taining proper nutrition or diets and participa-ting in sports;

४ "indifferent" - a group of people who take painkillers, consult pharmacists at the nearest pharmacy and, if the pain subsides, will not take further actions.

In general, respondents are supportive of Internet diagnostics, believing, like doctors, that this trend is the future. Respondents were asked to select the factors contributing or impeding the development of Internet diagnostics (multiple binary response). The proposed factors were previously derived from analysis of the in-depth interviews with physicians and pharmacists. The majority of respondents easily noted the factors behind the development of Internet diagnostics and only one third of respondents noted the factors "against" it ( Table 3).

In order to identify the most significant factors that affect the willingness to use electronic or Internet applications for disease diagnosis, factor analysis was performed (Table 4). 


\section{Factors contributing to or impeding the development of Internet diagnostics}

\begin{tabular}{|c|c|}
\hline Factors impeding the development & Factors contributing to the development \\
\hline $\begin{array}{l}\text { - Fear of technical problems (39.5\% of respondents); } \\
\text { - Self-treatment (35\%); } \\
\text { - Incorrect diagnosis (35\%); } \\
\text { - Misleading: intentional or accidental (32\%); } \\
\text { - Incorrect state assessment ( } 30.5 \%) ; \\
\text { - Incorrect use of medicines (dosage) (22.5\%); } \\
\text { - The use of drugs that are incompatible with each } \\
\text { other ( } 21.5 \%) ; \\
\text { - Excessive use of the drug, possible allergy (20\%) }\end{array}$ & $\begin{array}{l}\text { - "Digital" generation (23\% of respondents); } \\
\text { - Maintenance of a healthy life style (26.5\%); } \\
\text { - Control of doctors' work (28\%); } \\
\text { - Unwillingness to consult a doctor (28\%); } \\
\text { - Development of self-diagnosis and self-education (34\%); } \\
\text { - Reviews and instructions of preparations }(52 \%) \\
\text { - Availability: saving time and money; in any place: } \\
\text { both at work and at home (53\%); } \\
\text { - Informative / incomplete information from doctors (56\%). }\end{array}$ \\
\hline
\end{tabular}

\section{Rotated component matrix}

\begin{tabular}{|c|c|c|c|c|c|}
\hline \multirow{2}{*}{ № } & \multirow{2}{*}{ Factors } & \multicolumn{4}{|c|}{ Component } \\
\hline & & 1 & 2 & 3 & 4 \\
\hline 1 & $\begin{array}{l}\text { Availability: saving time and } \\
\text { money; in any place: both at } \\
\text { work and at home }\end{array}$ & .613 & & & \\
\hline 2 & Informative & .595 & & & \\
\hline 3 & $\begin{array}{l}\text { Maintenance of a healthy life } \\
\text { style }\end{array}$ & .579 & & & \\
\hline 4 & $\begin{array}{l}\text { Development of self-diagnosis } \\
\text { and self-education }\end{array}$ & .551 & & & \\
\hline 5 & Incomplete information & .511 & & & \\
\hline 6 & Control of the work of doctors & & .583 & & \\
\hline 7 & $\begin{array}{l}\text { Reviews and instructions } \\
\text { of preparations }\end{array}$ & & .564 & & \\
\hline 8 & Unwillingness to consult a doctor & & .532 & & \\
\hline 9 & $\begin{array}{l}\text { Incompleteness of information } \\
\text { from doctors: lack of information } \\
\text { about the threats of the disease } \\
\text { and the possible consequences } \\
\text { of treatment }\end{array}$ & & .503 & & \\
\hline 10 & $\begin{array}{l}\text { Excessive use of the drug, } \\
\text { possible allergy }\end{array}$ & & & 622 & \\
\hline 11 & $\begin{array}{l}\text { Misleading: intentional } \\
\text { or accidental }\end{array}$ & & & .568 & \\
\hline 12 & Incorrect state assessment & & & .565 & \\
\hline 13 & Self-treatment & & & .517 & \\
\hline 14 & $\begin{array}{l}\text { Incorrect use of medicines, } \\
\text { the use of incompatible drugs }\end{array}$ & & & .512 & \\
\hline 15 & Incorrect diagnosis & & & .502 & \\
\hline 16 & Fear of technical problems & & & .480 & \\
\hline 17 & $\begin{array}{l}\text { Rapid growth of Internet } \\
\text { self-diagnostics }\end{array}$ & & & & 561 \\
\hline 18 & Digital generation & & & & .501 \\
\hline
\end{tabular}

Table 4. The final factors were included in the regression model demonstrating the impact of factors on the willingness to use electronic or online applications for disease diagnosis (willingness to use, WTU):

$$
\begin{aligned}
W T U= & 5.765+0.341 \cdot V_{1}+0.385 \cdot V_{2}- \\
& -0.275 \cdot V_{3}+0.291 \cdot V_{4},
\end{aligned}
$$

where $V_{1}$ - usefulness of electronic and/or Internet applications for diagnosis;

$V_{2}$ - control of doctors and treatment;

$V_{3}-$ incorrect diagnosis via electronic and/or Internet applications;

$V_{4}$ - commitment to the Internet.

In other words, some respondents are afraid to incorrectly diagnose or determine treatment with the help of electronic or Internet applications, which can cause a deterioration of their condition. Thus, all the conclusions made earlier are confirmed.

\section{Conclusion}

In our study, we identified the patterns of patient behavior when using electronic applications and Internet resources for selfdiagnosis, as well as factors that contribute to or impede the development of such use. To this end, the authors of the paper carried out a number of studies: qualitative content analysis of medical web applications, 40 in-depth interviews with doctors and pharmacists, a mini focus group with representatives of the health service and an online survey of two hundred respondents in the social network Facebook. 
Typical (the most common) patterns of patients' behavior regarding the use of electronic applications and Internet resources in the medical field are "traditionalists" (with "doubters" subgroup), "searchers," and "generation Y".

The percentage of citizens who are ready to practice self-diagnosis and self-treatment using electronic applications and Internet resources is significant. Thus $50 \%$ of respondents consider it right to read information about the disease or conduct a self-diagnosis before visiting the doctor, $28 \%$ of respondents have already used professional electronic applications and Internet resources in the field of medicine. "Generation Y" group, which is mostly focused on the new pattern of behavior, reaches a significant share of $30 \%$ and continues to grow rapidly.

The main drivers of growth in the use of electronic applications and Internet resources for self-diagnosis are:

$\diamond$ reluctance to see doctors (mistrust, long queues, poor service, the prescription of expensive or ineffective drugs);

increasing awareness of patient and, as a consequence, doctors' work control;

accessibility of electronic applications and Internet resources in the field of medicine;
$>$ dependence on Internet technologies and the desire to deal with the problem independently, thereby "saving time and money."

The main factors impeding the development of self-diagnosis using electronic applications and Internet resources are a high risk of incorrect diagnosis, which can be the result of (1) incorrect assessment ofone'sowncondition, (2) incomplete collection of anamnesis, (3) incomplete or incorrect semiotics (not all or excessive signs of the disease have been introduced in the program), (4) application failures. The consequence may be incorrect diagnosis or misapplication of drugs with the help of the program (allergy, excessive use, the use of incompatible drugs).

Doctors, pharmacists and consumers of medical services are favorably disposed towards Internet diagnostics, believing that this is the future of medicine.

In conclusion, considering the substantial percentage of citizens willing to engage in selfdiagnosis and self-treatment practice (using electronic applications and Internet resources and its anticipated growth), it is important to develop a set of measures to control the spread and possibly the certification of developed applications and Internet resources to minimize possible negative consequences for patients.

\section{References}

1. Greenspun H., Coughlin S. (2012) mHealth in a mWorld. How mobile technology is transforming health care / Deloitte Center for Health Solutions. Available at: https://www2.deloitte.com/content/dam/Deloitte/us/ Documents/life-sciences-health-care/us-lhsc-mhealth-in-an-mworld-103014.pdf (accessed 01 October 2017).

2. Arthur D. Little (2016) Succeeding with digital health. Winning offerings and digital transformation. Available at: http://www.adlittle.com//sites/default/files/viewpoints/ADL_2016_Succeeding_With_Digital_Health. pdf (accessed 01 October 2017).

3. Ventola C.L. (2014) Mobile devices and apps for health care professionals: Uses and benefits. Pharmacy and Therapeutics, vol. 39, no. 5, pp. 356-364.

4. Lee E., Han S. (2015) Determinants of adoption of mobile health services. Online Information Review, vol. 39, no. 4, pp. 556-573.

5. Laws D. (2015) What value does the pharmaceutical industry bring to health care? Journal of Creating Value, vol. 1, no. 1, pp. 79-90.

6. Jutel A., Lupton D. (2015) Digitizing diagnosis: a review of mobile applications in the diagnostic process. Diagnosis, vol. 2, no. 2, pp. 89-96.

7. Khuntia J., Yimb D., Tanniru M., Lim S. (2017) Patient empowerment and engagement with a health infomediary. Health Policy and Technology, vol. 6, no. 1, pp. 40-50.

8. Carman K.L., Workman T.A. (2017) Engaging patients and consumers in research evidence: Applying the conceptual model of patient and family engagement. Patient Education and Counseling, vol. 100, no. 1, pp. $25-29$. 